Elsevier Biomedical Press

BBA Report

BBA 30035

\title{
THE ROLE OF THE TRANSITION BETWEEN NEUTRAL AND BASIC FORMS OF HUMAN SERUM ALBUMIN IN THE KINETICS OF THE BINDING TO WARFARIN
}

\author{
JOSEPHINA M.H. KREMER*, GESINA BAKKER and JAAP WILTING \\ Department of Pharmaceutical Chemistry, Subfaculty of Pharmacy, State University of Utrecht, Catharijnesingel 60, 351I GH Utrecht \\ (The Netherlands)
}

(Received June 15th, 1982)

Key words: Human serum albumin; Warfarin; Neutral-to-base transition; Association

Between pH 6 and 9 in the kinetics of the binding of warfarin to human serum albumin a two-step mechanism operates: a diffusion-controlled step, followed by a much slower step during which the stable warfarin-albumin complex is formed. The association rate constant for the formation of the warfarin-albumin complex depends on the transition between neutral and basic forms of the albumin.

A pH-dependent conformational change in bovine and human serum albumin around physiological $\mathrm{pH}$ is often mentioned in the literature (see Wilting et al. [1, 2] for references). There is evidence for the existence of two conformational states, the $\mathrm{N}$ form occurring mainly below neutral $\mathrm{pH}$ and the $\mathrm{B}$ form at higher $\mathrm{pH}$. The conformational change between these two states is therefore called the neutral-to-base or N-B transition. In this paper we describe the effect that this N-B transition has on the kinetics of the binding of warfarin (W) to human serum albumin (P).

In a recent paper [3] we reported on the kinetics of the binding of warfarin to human serum albumin at $\mathrm{pH} 8.7$, where the albumin is in the $\mathrm{B}$ conformation. We produced evidence that the kinetics of the binding proceed in two steps, i.e., a diffusion-controlled step, followed by the considerably slower step, during which the stable warfarin-albumin complex (WP) is formed. This binding process can be summarized in the following reaction scheme [3]:

$\mathrm{W}+\mathrm{P} \underset{k_{-1}}{\stackrel{k_{1}}{\rightleftarrows}}[\mathrm{W} \ldots \mathrm{P}]^{\ddagger} \underset{k_{-2}}{\stackrel{k_{2}}{\rightleftarrows}} \mathrm{WP}$

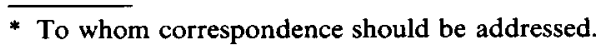

This proposed reaction mechanism was found to be based on the dependence of the observed rate constant $\left(k_{\text {obs }}\right)$ on the albumin concentration [P].

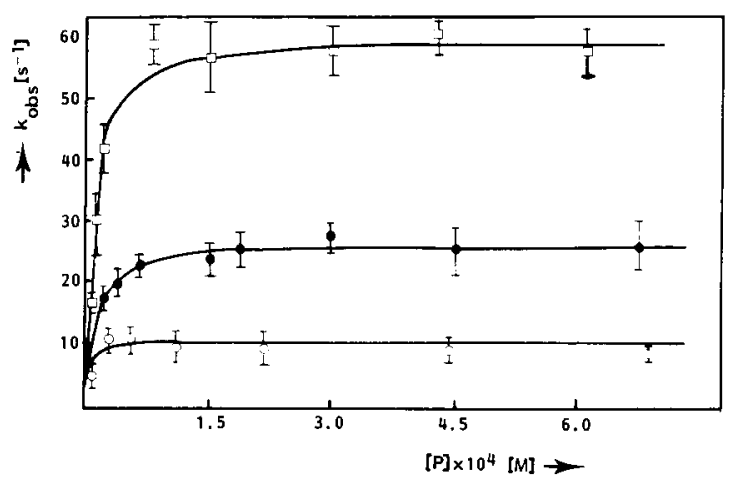

Fig. 1. Observed rate constant ( $\left.k_{\text {obs }}\right)$ vs. human serum albumin concentration $[\mathrm{P}]$ for the reaction between warfarin and albumin; for preparation and pre-treatment of this human serum albumin, see Refs. 3 and 8; the stopped-flow experiments were carried out as described previously [3]; ratio warfarin to albumin $(r)=0.01 ; 25^{\circ} \mathrm{C} ; \mathrm{pH} 6.2(0), 7.5(\bullet)$ and $8.7(\square)$, in phosphate or borate buffer, $I=0.1$; drawn curves are calculated by assuming a two-step reaction model as described previously [3]: intercept on the ordinate axis corresponds to $k_{-2}$; plateau level for $[\mathrm{P}]>1.5 \cdot 10^{-5} \mathrm{M}$ corresponds to $k_{2}+$ $k_{-2} ; K_{1}$ can be estimated from the point of intersection of the two straight lines, which can be drawn through the experimental points [3]; the binding constant $\left(K_{\mathrm{eq}}\right)$ can be calculated by using $K_{\mathrm{eq}}=K_{1} \cdot k_{2} / k_{-2}$, as described previously [3]. 
Fig. 1 shows the dependence at $\mathrm{pH} 8.7$, together with the dependence at $\mathrm{pH} 6.2$ and the dependence at $\mathrm{pH}$ 7.5. This dependence of $k_{\mathrm{obs}}$ on [P] was found to occur over the whole $\mathrm{pH}$ range from 6 to 9 . Almost $100 \%$ of the albumin is in the $\mathrm{N}$ conformation at $\mathrm{pH} 6.2$, but at $\mathrm{pH} 7.5$ only about $35 \%$; both results were derived from $\mathrm{CD}$ measurements, as described previously [2]. One can therefore conclude from Fig. 1 that the proposed mechanism for the kinetics of the binding between

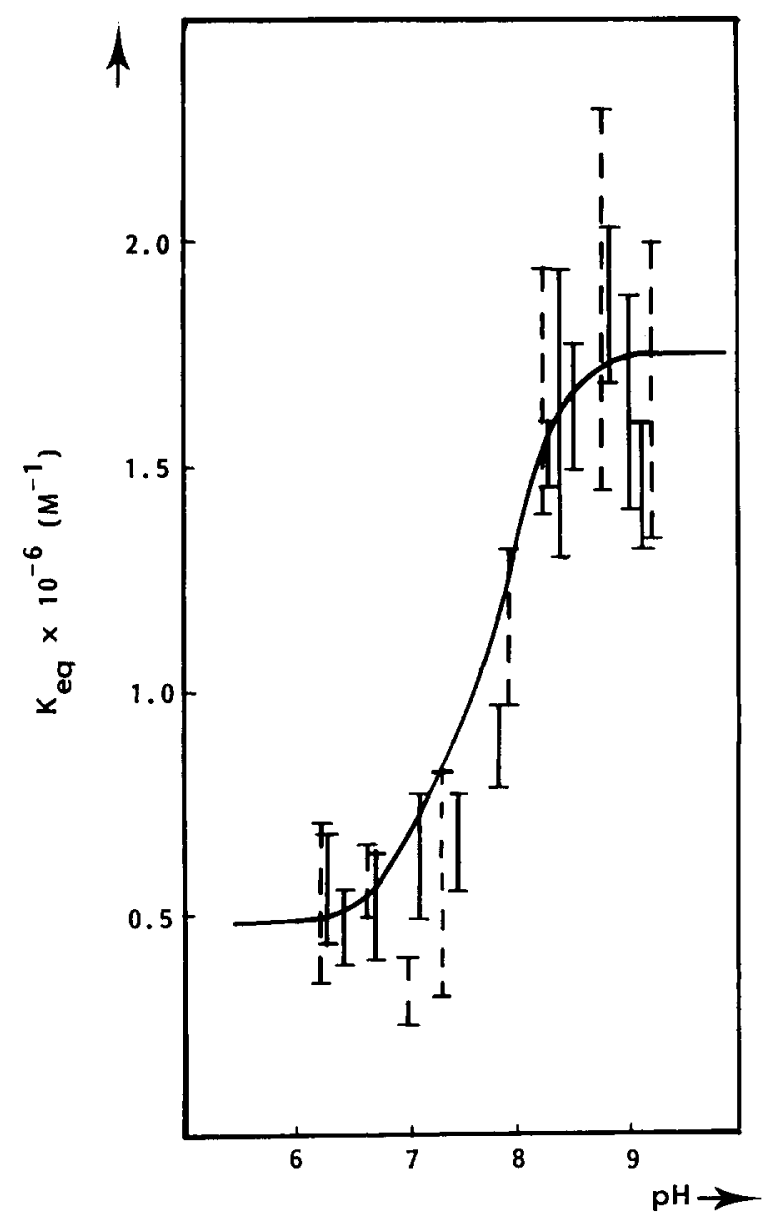

Fig. 2. Binding constant ( $K_{\mathrm{eq}}$ ) for the binding of warfarin to albumin; conditions as in Fig. 1; ( $\longmapsto$ ) calculated $K_{\text {eq }}$, based on equilibrium dialysis experiments as described earlier [2]; $(+\ldots-1)$ calculated $K_{\text {eq }}$, based on the parameters $k_{2}$, $k_{-2}$ and $K_{1}$, which can be determined from kinetic experiments, as shown in Fig. 1 (see also Ref. 3); drawn curve is calculated by assuming a two-state model with $\mathrm{pH}$-independent binding constants $K_{\mathrm{N}}$ and $K_{\mathrm{B}}$ for the $\mathrm{N}$ and the $\mathrm{B}$ conformation, respectively, as described earlier [2]. warfarin and albumin to the warfarin site (also called site I) on the albumin molecule in the B conformation also holds when the protein is in the $\mathrm{N}$ conformation.

Recently we found that with the help of the proposed reaction mechanism we could derive the binding constant $\left(K_{\text {eq }}\right)$ for the binding of warfarin to albumin at $\mathrm{pH} 8.7$ from the kinetic measurements [3]; the value we found agrees well with the binding constant determined with equilibrium dialysis. The results of such calculations for $\mathrm{pH}$ values between 6 and 9 are shown in Fig. 2. It can be seen from the figure that at all $\mathrm{pH}$ values there is good agreement between the binding constants determined kinetically and those obtained with equilibrium dialysis.

It should be noticed that in terms of the kinetic model the binding constant consists of the parameters $K_{1}, k_{2}$ and $k_{-2}$ (see the reaction scheme and also the legend to Fig. 1). The binding constant $\left(K_{\text {eq }}\right)$ depends on the conformational state of the albumin [2]. It is likely that this conformation effect on $K_{\text {eq }}$ has its origin in $k_{2}$ or $k_{-2}$, since, in the $\mathrm{pH}$ dependence of the rate constants $k_{1}$ and

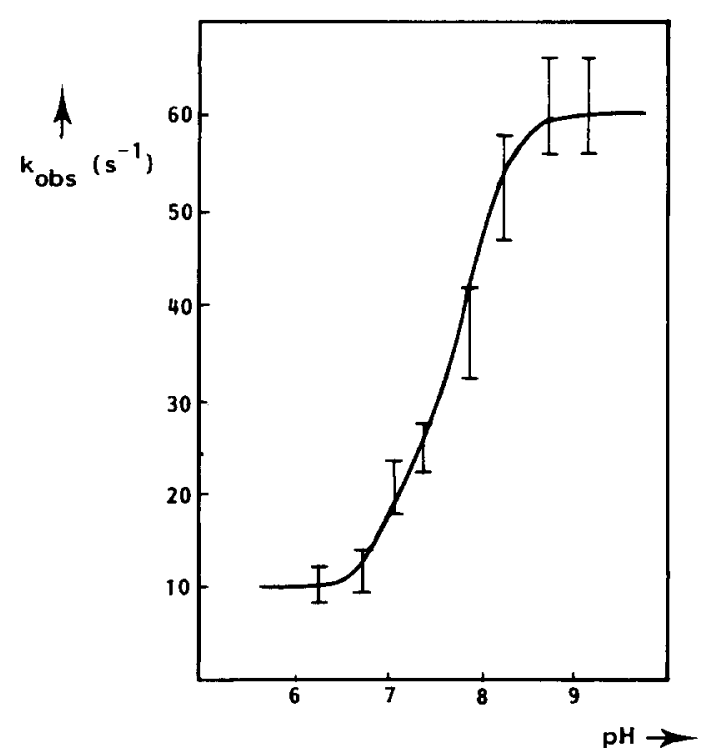

Fig. 3. Observed rate constant $\left(k_{\text {obs }}\right)$ for $[\mathrm{P}]>1.5 \cdot 10^{-5} \mathrm{M}$, corresponding to $k_{2}+k_{-2}$ (see also Ref. 3), vs. pH; conditions as in Fig. 1; drawn curve is calculated by assuming that the $\mathrm{pH}$ dependence of $k_{\mathrm{obs}}$ is due to the N-B transition of the albumin, as described by Eqn. 1 (see also text). 
$k_{-1}$ in the diffusion-controlled step, changes in the net charge of the protein will play a dominant role $[4,5]$. The rate constant $k_{-2}$, which is represented by the intercept of the curves in Fig. 1 with the ordinate axis, appears to be independent of the $\mathrm{pH}$. Therefore the dependence of $K_{\mathrm{eq}}$ on the state of the $N \rightleftarrows B$ equilibrium must have its origin in $k_{2}$, which can be derived from the plateau levels of the curves in Fig. 1 (see the legend to that figure, and Ref. 3). Since, for the corresponding concentrations of the protein $k_{\mathrm{obs}}=k_{2}+k_{-2}$ and $k_{-2}$ appears to be independent of $\mathrm{pH}$, a $\mathrm{pH}$ dependence of $k_{2}$, if it exists, will lead to a $\mathrm{pH}$ dependence of $k_{\mathrm{obs}}$. It can be seen from Fig. 3 that the value of $k_{\mathrm{obs}}$ is indeed dependent on the $\mathrm{pH}$. If this $\mathrm{pH}$ dependence of $k_{\mathrm{obs}}$ is due to the N-B transition, then the curve in Fig. 3 can be fitted with [2]:

$k_{\mathrm{obs}}=(1-\alpha) k_{\mathrm{obs}}^{\mathrm{N}}+\alpha k_{\mathrm{obs}}^{\mathrm{B}}$

where $\alpha$ is the fraction of the protein in the B form and $k_{\mathrm{obs}}^{\mathrm{N}}$ and $k_{\mathrm{obs}}^{\mathrm{B}}$ are the observed rate constants in the $\mathrm{N}$ and $\mathrm{B}$ conformations, respectively. This equation is valid, when the ligand molecule to be studied has no marked effect on the state of the $\mathrm{N} \Rightarrow \mathrm{B}$ equilibrium on binding to the albumin molecule; warfarin fulfils this condition [1,2]. Since $\alpha$ can be derived from CD measurements, as described previously [2], the pH dependence of $k_{\text {obs }}$ can be calculated. Fig. 3 shows that there is good agreement between calculated and experimental $\left(k_{\mathrm{obs}}, \mathrm{pH}\right)$ profiles. This result supports the hypothesis that the sensitivity of the value of $K_{\mathrm{eq}}$ to the conformational state of albumin is due to $k_{2}$, which is the rate constant of the association reaction between warfarin and albumin leading to the stable complex. We found (data not shown) that $\mathrm{Ca}^{2+}$ and $\mathrm{Cl}^{-}$ions affect the $\mathrm{pH}$ dependence of $k_{2}$ in the same way as reported previously for the $\mathrm{pH}$ dependence of $K_{\mathrm{eq}}[1,2]$. This effect of $\mathrm{Ca}^{2+}$ and $\mathrm{Cl}^{-}$on the $\mathrm{pH}$ dependence of $K_{\mathrm{eq}}$ was shown to be due to a change in the state of the $\mathrm{N} \rightleftarrows \mathrm{B}$ equilibrium by these ions. The parallel in the effects of $\mathrm{Ca}^{2+}$ and $\mathrm{Cl}^{-}$on the $\mathrm{pH}$ dependence of $K_{\text {eq }}$ and of $k_{\text {obs }}$ further supports the contention that $k_{2}$ is sensitive to the N-B transition.

As we said above, the main effect of the N-B transition on $K_{\text {eq }}$ cannot have its origin in the kinetic constants $k_{1}$ and $k_{-1}$ of the diffusion-controlled step in the reaction mechanism. This statement needs further explanation. Following the lines of the theoretical treatment of a diffusion-controlled reaction given by Burgen [4] one might expect $k_{-1}$ to be affected to a lesser extent by the net charge of the protein than $k_{1}$. Furthermore we found that $k_{-2}$ is independent of the conformational state of the albumin. It is therefore likely that $k_{-1}$ is also independent of the $\mathrm{pH}$. On the other hand one can expect $k_{1}$ to be very sensitive to the $\mathrm{pH}$, since the value of $k_{1}$ will depend strongly on the net charge of the protein $[3,5]$, due to a change in the electrostatic interactions between the charged species (warfarin having its $p K_{\mathrm{a}}$ at 5.0 is singly negatively charged over the $\mathrm{pH}$ range under investigation). Since the net charge of the protein decreases with $\mathrm{pH}$ (isoionic point at about $\mathrm{pH} 5.2$ and $\mathrm{d} Z_{\mathrm{H}} / \mathrm{dpH}$ is roughly -6 for the $\mathrm{pH}$ region 6 to $9, Z_{\mathrm{H}}$ being the net charge of the protein [3]), an increase in electrostatic repulsion between warfarin and albumin can be expected. Therefore $k_{1}$ will decrease with $\mathrm{pH}$ and so will $K_{1}$; this is indeed what we found (data not

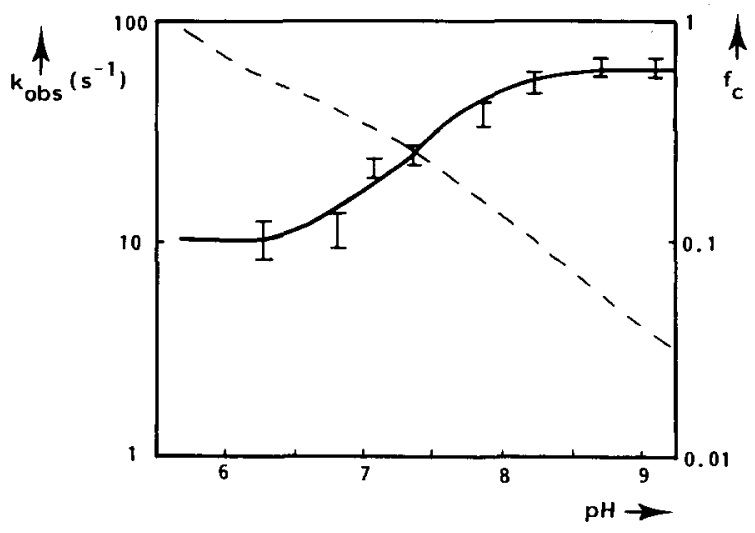

Fig. 4. ( $\longmapsto$ ) experimentally determined rate constant vs. $\mathrm{pH}$ for $[\mathrm{P}]>1.5 \cdot 10^{-5} \mathrm{M}$; conditions as in Fig. 1; drawn line is calculated by assuming that the $\mathrm{pH}$ dependence of observed rate constant is due to the N-B transition of the albumin, as described by Eqn. 1; dashed line is calculated by assuming that the reaction that occurs is a diffusion-controlled one (see text and Ref. 3); for explanation of $f_{c}$ see text and Refs. 3 and 5; it should be noted that $f_{c}$ in this figure has not been corrected for a double layer effect due to the presence of salts $(I=0.1)$; in the case of $I=0.1$ the slope of the dashed line ( $f_{\mathrm{c}} \mathrm{vs.} \mathrm{pH}$ ) will be less steep but this does not alter the conclusion drawn. 
shown). In Fig. 4 the theoretical dependence of $k_{1}$ based on an increase in electrostatic repulsion between the reacting species as expressed by the Debye factor $f_{\mathrm{c}}[3]$ is shown together with the $\mathrm{pH}$ dependence of $k_{\text {obs. }}$. It can be seen from the figure that the curves for the $\mathrm{pH}$ dependences of $k_{1}$ and $k_{\text {obs }}$ run in opposite directions. This factor is additional support for the proposed reaction mechanism.

Finally it should be noted that the absolute values of the rate constants and therefore also of the binding constant will depend on the albumin sample [6]. But we found that the proposed reaction mechanism holds not only for the albumin sample used in this study (for preparation and pre-treatment, see Refs. 3 and 7), but also for samples which are commercially available (from Sigma, St. Louis, MO, U.S.A.; Biotest, Frankfurt am Main, F.R.G. (see also Ref. 8); Kabivitrium, Stockholm, Sweden) and even for bovine serium albumin (from Sigma).

From a pharmacokinetic point of view the rate of dissociation of the warfarin-albumin complex is of interest. The value of $k_{-2}$ as derived from the curves in Fig. 1 is about $3 \mathrm{~s}^{-1}$, which corresponds to a $t_{1 / 2}$ of about $0.2 \mathrm{~s}$. Since this value holds both in the $\mathrm{N}$ and in the $\mathrm{B}$ conformation and the transit time of albumin in the liver is about $10 \mathrm{~s}$ [9], the rate of dissociation of the warfarin-albumin complex is unlikely to be the rate-limiting step in the metabolic rate of warfarin. This statement holds irrespective of the conformational state of the albumin. However, in the steady state the free concentration of warfarin at a given total concentration of the drug will depend on the state of the $\mathrm{N} \rightleftharpoons \mathrm{B}$ equilibrium due to the difference in affinity of the drug to albumin in the $\mathrm{N}$ and in the $\mathrm{B}$ conformation. This equilibrium state is likely to alter in tissues and organs where $\mathrm{pH}$ changes can occur, such as the liver (for references see Ref. 3). To elucidate the precise role of the N-B transition in the rate of metabolic processes and also in the transport function of albumin, studies on the kinetics of the N-B transition are in progress.

\section{References}

I Wilting, J., Weideman, M.M., Roomer, A.C.J. and Perrin, J.H. (1979) Biochim. Biophys. Acta 579, 469-473

2 Wilting, J., Van der Giesen, W.F., Janssen, L.H.M., Weideman, M.M., Otagiri, M. and Perrin, J.H. (1980) J. Biol. Chem. 255, 2032-3037

3 Wilting, J., Kremer, J.M.H., IJzerman, A.P. and Schulman, S.G. (1982) Biochim. Biophys. Acta 706, 96-104

4 Burgen, A.S.U. (1966) J. Pharm. Pharmacol. 18, 137-149

5 Wilting, J., Nauta, H. and Braams, R. (1971) FEBS Lett. 16, $36-40$

6 Dröge, J.H.M., Wilting, J. and Janssen, L.H.M. (1982) Biochem. Pharmacol., in the press

7 Kremer, J.M.H. (1982) Vox Sang. 42, 223-224

8 Rietbrock, N. and Lassmann, A. (1980) Naunyn-Schmiedeberg's Arch. Pharmacol. 313, 269-274

9 Gilette, J.R. and Mitchel, J.R. (1975) Concepts in Biochemical Pharmacology, Part 3, p. 37, Springer-Verlag, Berlin 